\title{
Synthesis, Spectral Characterization, and Anti-Tumor Activity of Some Pyrazole Derivatives ${ }^{+}$
}

\author{
Christina Marie Zalaru 1,*, Maria Marinescu 1, Florea Dumitrascu 2, Constantin Draghici 2, \\ Rodica Tatia ${ }^{3}$, Lucia Moldovan ${ }^{3}$, Alina Constantinescu ${ }^{1}$ and Irina Dumitrescu ${ }^{1}$ \\ 1 Department of Organic Chemistry, Biochemistry and Catalysis, Faculty of Chemistry, \\ University of Bucharest, 90-92 Panduri Road, Bucharest Romania, RO-050663 Bucharest, Romania; \\ maria.marinescu@chimie.unibuc.ro (M.M.); alinaconstantinescu21@gmail.com (A.C.); \\ irinadumi1@gmail.com (I.D.) \\ 2 Institute of Organic Chemistry “C.D. Nenitescu”, 202B Spl Independentei, RO-060023 Bucharest, Romania; \\ fdumitra@yahoo.com (F.D.); cst_drag@yahoo.com (C.D.) \\ 3 Department of Cellular and Molecular Biology, National Institute of Research and Development for \\ Biological Sciences, 296 Splaiul Independenței, RO-060031 Bucharest, Romania; \\ rodica.tatia@gmail.com (R.T.); moldovanlc@yahoo.com (L.M.) \\ * Correspondence: christina.zalaru@chimie.unibuc.ro or chmazalaru@gmail.com \\ † Presented at the 16th International Symposium "Priorities of Chemistry for a Sustainable Development" \\ PRIOCHEM, Bucharest, Romania, 28-30 October 2020.
}

Published: 18 November 2020

Keywords: organic synthesis; pyrazoles; NMR spectroscopy; cytotoxicity

\section{Introduction}

Cancer is a terrible disease that is spread around the world. Chemotherapy remains a significant way of treating cancerous diseases. Although some impressive progress has been made in cancer therapy, drug resistance and toxicity, the development of new anticancer chemotherapeutic agents is being sought $[1,2]$.

\section{Materials and Methods}

Commercial reagents have been used in the synthesis of intermediate pyrazolic compounds. All synthesized pyrazolic compounds were characterized by IR, ${ }^{1} \mathrm{H}-\mathrm{NMR}{ }^{13} \mathrm{C}-\mathrm{NMR}, \mathrm{UV}-\mathrm{Vis}, \mathrm{MS}$, elemental analysis, and tested in vitro for their anti-tumor activity.

\section{Results}

In this study three series of pyrazole derivatives were synthesized in two steps with good yields:

In the first step, pyrazoles reacted with a aqueous $30 \%$ formaldehyde solution to give the 1-(hydroxymethyl)pyrazole derivatives [3]. In the second step, the 1-hydroxymethyl-pyrazoles reacted with, aromatic amines giving pyrazole Mannich bases [4,5].

The structures of all compounds were confirmed by ${ }^{1} \mathrm{H},{ }^{13} \mathrm{C}-\mathrm{NMR}, \mathrm{FTIR}, \mathrm{UV}-\mathrm{VIS}$ spectra and elemental analysis.

Some compounds were tested in vitro for their cytotoxic activity on normal NCTC cells, and their anti-tumor activity in a culture of human cervix carcinoma Hep-2 cells at different concentrations of the sample for $48 \mathrm{~h}$.

Some new benzimidazole Mannich bases was synthesized and characterized [6]. 


\section{References}

1. Cherukupalli, S.; Karpoormath, R.; Chandrasekaran, B.; Hampannavar, G.A.; Thapliyal, N.; Palakollu, V.N. An insight on synthetic and medicinal aspects of pyrazolo[1,5-a] pyrimidine scaffold. Eur. J. Med. Chem. 2017, 126, 298-234.

2. Hong, D.; Meiling, H.; Jianqiang, Q.; Ji, L.; Chi, M.; Yangyang, L.; Guxu, M.; Ting, Z.; Senling, W.; Yujun, S.; et al. Excellent antitumor and antimetastatic activities based on novelcoumarin/pyrazole oxime hybrids. Eur. J. Med. Chem. 2019, 166, 470-479.

3. Zalaru, C.; Putina, G.; Dumitrascu, F.; Draghici, C. New Mannich bases with pharmacological activity. Rev. Chim. 2007, 58, 773-775.

4. Marinescu, M.; Tudorache, D.G.; Marton, G.I.; Zalaru, C.M.; Popa, M.; Chifiriuc, M.C.; Stavarache, E.; Constantinescu, C. Density functional theory molecular modeling, chemical synthesis, and antimicrobial behavior of selected benzimidazole derivatives. J. Mol. Struct. 2017, 1030, 463-471.

5. Zalaru, C.; Dumitrascu, F.; Draghici, C.; Tarcomnicu, I.; Tatia, R.; Moldovan, L.; Chifiriuc, M.C.; Lazar, V.; Marinescu, M.; Nitulescu, M.G.; et al. Synthesis, spectroscopic characterization, DFT study and antimicrobial activity of novel alkylaminopyrazole derivatives. J. Mol. Struct. 2018, 1156, 12-21.

6. Marinescu, M.; Cinteza, L.O.; Marton, G.I.; Chifiriuc, M.C.; Popa, M.; Stanculescu, I.; Zalaru, C.-M.; Stavarache, C.-E. Synthesis, density functional theory study and in vitro antimicrobial evaluation of new benzimidazole Mannich bases. BMC Chem. 2020, 14, 45.

Publisher's Note: MDPI stays neutral with regard to jurisdictional claims in published maps and institutional affiliations.

(C) 2020 by the authors. Licensee MDPI, Basel, Switzerland. This article is an open access article distributed under the terms and conditions of the Creative Commons Attribution (CC BY) license (http://creativecommons.org/licenses/by/4.0/). 